\title{
SCHOOL-BASED MENTAL HEALTH: WHAT AND WHY IT IS NEEDED
}

\author{
Usmi Karyani' ${ }^{1,2)}$, Subandi3), Ira Paramastri3), Nanik Prihartanti3) \\ 1)Doctoral Program of Psychology, Universitas Gadjah Mada \\ 2)Faculty of Psychology, Universitas Muhammadiyah Surakarta \\ 3)Faculty of Psychology, Universitas Gadjah Mada
}

\begin{abstract}
Background: Over the years there has been an increase in mental health problems in children and adolescents all over the world. To anticipate the increasing number of mental health problems in children and adolescents, various parties, including World Health Organization (WHO), encourage to develop school-based mental health services (SBMH). The issue of SBMH has become quite widespread in the past two decades. This study aimed to provide an understanding concept of SBMH.

Subjects and Method: This was a literature study to critically analyze and describe the reasons of what and why SBMH is needed. The study was done through summary, classification, and comparison of prior studies, reviews of literature, and theoretical articles.

Results: School-based programs offered the promise of improving access to diagnosis of and treatment for the mental health problems of children and adolescents. School-based mental health services (SBMH) was quite effective in addressing health problems in children and adolescents. Unfortunately, many mental health researchers and practitioners in Indonesia were not familiar about the concept of SBMH.

Conclusion: By understanding the concept of SBMH, it is hoped that more mental health researchers and practitioners are intere
\end{abstract}

Key words: mental health, promotion, school-based mental health

\section{Correspondence:}

Usmi Karyani. Doctoral Program of Psychology, Universitas Gadjah Mada/ Faculty of Psychology, Universitas Muhammadiyah Surakarta, Surakarta, Central Java. Email: uk257@ums.ac.id. Mobile: 081325872920.

The 5th International Conference on Public Health

Best Western Premier Hotel, Solo, Indonesia, February 13-14, 2019 | 230

https://doi.org/10.26911/theicph.2019.02.40 